\title{
A new TK model approach to assess the effect of migration on copper toxicokinetics in inbred populations of the flour beetle, Tribolium castaneum
}

\author{
Sebastian Żmudzki ${ }^{1} \cdot$ Natnael T. Hamda $^{2} \cdot{\text { Patrycja Gibas }- \text { Tybur }^{1}}^{1}$
}

Received: 10 July 2016 / Accepted: 21 April 2017 / Published online: 26 May 2017

(c) The Author(s) 2017. This article is an open access publication

\begin{abstract}
The aim of the study was to determine the influence of migration on copper $(\mathrm{Cu})$ kinetics of male Tribolium castaneum after 25 generations of exposure for $\mathrm{Cu}-$ adapted and non-Cu-adapted inbred lines. Adapted lines were kept on a flour medium contaminated with $1000 \mathrm{mg}$ $\mathrm{Cu} \mathrm{kg}^{-1}$. A medium contaminated with $2000 \mathrm{mg} \mathrm{Cu} \mathrm{kg}{ }^{-1}$ of copper was used during the intoxication phase. Based on our data and literature reports, we introduced a new twophase four-stage toxicokinetics (TK) model. The intoxication phase was successfully divided into three stages with separate assimilation rate constant $\left(\mathrm{k}_{\mathrm{a}}\right)$ and elimination rate constant $\left(\mathrm{k}_{\mathrm{e}}\right)$ values. The influence of migration was examined by comparing $\mathrm{k}_{\mathrm{a}}$ and $\mathrm{k}_{\mathrm{e}}$ parameters confidence intervals. In non-contaminated environments, migrants significantly increased $k_{a}$ and $k_{e}$ values in the second stage. Migrants decreased the maximum $\mathrm{Cu}$ accumulation observed in the experiment. The results indicated that the TK model must show high goodness-of-fit to be a useful tool for comparing treatments.
\end{abstract}

Keywords Copper tolerance $\cdot$ TK model $\cdot$ Copper adaptation $\cdot$ Midgut physiology

Electronic supplementary material The online version of this article (doi:10.1007/s00128-017-2093-7) contains supplementary material, which is available to authorized users.

Sebastian Żmudzki

sebspiders@wp.pl; sebastian.zmudzki@uj.edu.pl

Natnael T. Hamda

tnatnael@gmail.com

1 Institute of Environmental Sciences, Jagiellonian University, Gronostajowa 7, 30-387, Kraków, Poland

2 Department of Fisheries, Wildlife, and Conservation Biology, University of Minnesota, St. Paul, MN 55108, USA
Anthropogenic activity has massively changed natural environments. Large amounts of natural elements, including trace metals, have been relocated from deep deposits to surface soil layers and water bodies (Newman 2009).

One of the most abundant metals in the environment is copper. $\mathrm{Cu}$ is an essential element that is responsible for many metabolic processes, but is toxic at high doses. It is introduced to the environment in large quantities through fossil fuels combustion, mining and smelting activities, and through the application of fertilizers, sewage sludge, algicides, fungicides and molluscicides (Flemming and Trevors 1989). Multi-generational exposure to elevated levels of metals can be a selection factor and can lead to the evolution of adaptations that enable organisms to cope with elevated metal levels in the environment (Posthuma et al. 1992).

A second important problem caused by human activity is habitat fragmentation. It can pose a serious threat to the survival of animal populations and lead to inbreeding (Reed 2004) and inbreeding depression manifested by decreases in productivity, the viability of individuals, lifespan, and finally in population size decrease. The cooccurrence of habitat fragmentation and metal pollution is common across urbanized and industrialized areas. Limited population sizes and rapid selection for increased resistance to pollutants lead to a decrease of genetic diversity and can intensify inbreeding depression (Armbruster 2005). The threat of local population extinction stemming from small population size and inbreeding can be mitigated by immigrations (Carlson et al. 2014). Immigrants can significantly elevate heterozygosity and the vitality of progeny however, immigrants arriving from different environments that do not bear beneficial adaptations can also negatively affect small populations adapted to pollution or local microhabitats (Lopez et al. 2009). 
In polluted environments, one of the primary factors that determine an individual's performance is its toxicokinetics (TK) response. It provides a general overview of the physiology of organisms with respect to toxicant management, detoxification, acclimation or adaptation and the efficiency of defense mechanisms (Eagisz et al. 2005; Posthuma and Van Straalen 1993; Postma et al. 1996), or differences between species (Janssen et al. 1991). The objective of this study was to assess the influence of migrations between small, inbred $\mathrm{Cu}$-adapted and non-adapted lines of Tribolium castaneumon on $\mathrm{Cu}$ TK. The main questions were: do migrants cause heterosis, adaptation additivity or outbreeding depression and evolutionary rescue reduction in the first generation after migrations? Are these effects different in $\mathrm{Cu}$-adapted and non-adapted populations?

\section{Materials and Methods}

The research was based on 200 inbred lines of the flour beetle $T$. castaneum derived from a multi-generational selection experiment conducted for 25 generations in our laboratory. The lines were established from a highly polymorphic stock culture created by breeding individuals (for three generations) from cultures obtained from 12 laboratories around the world. From the stock culture, 25 individuals in the pupa stage were randomly sampled for each selection line and placed in vials filed with $5 \mathrm{~g}$ of flour medium for 18 days. Successfully emerged 20 adults were randomly selected to establish each line. They were placed in vials filed with $20 \mathrm{~g}$ of medium and laid eggs for three days. Eggs were incubated in $30^{\circ} \mathrm{C}$, after 21 days emerged pupae sampled (25 individuals) and this procedure was repeated for the next generation and repeated for all subsequent generations. The experimental lines were divided into two groups; 100 lines were kept in control selection environment (i.e., raised on non contaminated medium) and 100 lines were raised in copper contaminated selection environment (1000 mg kg-1 of $\mathrm{Cu}$ in medium). Calculated increase in the inbreeding coefficient over time, after 25 generations of isolation was $\Delta \mathrm{F}=0.47$ (Soule and Wilcox 1980). Preliminary studies (unpublished data) confirmed that there were significant inheritable differences between inbred populations selected and non-selected for $\mathrm{Cu}$ resistance.

After 22 generations, 20 lines were selected for the study from among the 200 inbred lines: ten of them from lines kept in non-contaminated selection environment and the other 10 from lines kept in $\mathrm{Cu}$-contaminated selection environment. The criterion of the selection was resistance to copper contamination measured by reproduction rate (the number of emerged adult progeny) in non-contaminated environment and environment contaminated with $3000 \mathrm{mg}$ $\left.\mathrm{kg}^{-1} \mathrm{Cu}\right)$.
After 25 generations of selection on each of the 20 lines chosen for the experiment, the founders of the next generation were randomly sampled in the pupa stage: 50 males and 50 females were incubated separately. After 21 days of incubation, mature animals from each line were assigned to one of seven different migration treatments: 'aftermigration lines' (AML) with no migrants (NM-control lines maintained under the same regime as in the main selection experiment), lines with $50 \%$ 'internal' migrants (IM50 - migrants taken from a randomly chosen line from the same selection environment), and lines with either $20 \%$ or $50 \%$ of 'external' migrants (EM20 and EM50-migrants derived from a line from different selection environment) (Fig. 1). According to the experiment setup, animals were assigned to the AML in adequate number in the same type of selection environment (residual individuals) or moved as migrants to the second selection environment (Fig. 1). Thus, 10 replicates per group (treatment) were established. Individuals assigned to a treatment were mixed (residual individuals and migrants) in $50 \mathrm{~mL}$ vials filed with appropriate medium. In each case there were 20 fertile founders with a sex ratio of $1: 1$. The beetles were kept on the same medium type as the ancestral population (50 g medium, 7 days of egg deposition). The F1 progeny were used for the TK experiment.

For kinetics experiment we randomly sampled 105 males in the pupa stage from each AML and incubated them. Mature animals, aged 41-49 days from oviposition were used in TK experiment. We allocated them into $100 \mathrm{~mL}$ plastic containers filled with medium contaminated according to kinetic experiment phase. The experiment was divided into two phases. During the contamination phase (28 days) the animals were kept on $\mathrm{Cu}$-contaminated medium (2000 $\mathrm{mg} \mathrm{kg}^{-1}$ ). Then they were switched onto the control medium at the start of the decontamination phase (12 days). The animals from the experimental cultures were sampled on the following days, determined from the start of the contamination phase: $0,0.5,1,1.5,2,4,6,8,12,16$, 20, 24 and 28. We used the same regime during the decontamination phase (sample days: 28.5, 29, 29.5, 30, 32, 34, 36 and 40). Each sample consisted of three individuals. The collected animals were starved for $24 \mathrm{~h}$ to empty the gut of contents, euthanized by freezing, and stored in a frozen state. For analyses of $\mathrm{Cu}$ concentration, the samples were prepared and analyzed according to standardized method (Bednarska and Stępień 2015). A reference material (Bovine liver SRM 1577c, NIST) was analyzed for eight replicates. The recovery for $\mathrm{Cu}($ mean $\% \pm \mathrm{SD})$ was $100.7 \% \pm 4.48 \%$.

All experimental cultures were maintained in conditions recommended for $T$. castaneum (Sokoloff 1974). The $\mathrm{Cu}$-contaminated medium was obtained by diluting $\mathrm{CuCl}_{2}$ (Copper (II) Chloride Dihydrate Pure p.a., POCH) in 
Fig. 1 Design of the migration experiment. After-migration lines $(A M L)$ : $N M$ no migrations, IM50 internal migrations (50\% migrants from the same selection environment), EM20 external migrations ( $20 \%$ migrants from different selection environment), EM50 external migrations (50\% migrants from different selection environment)

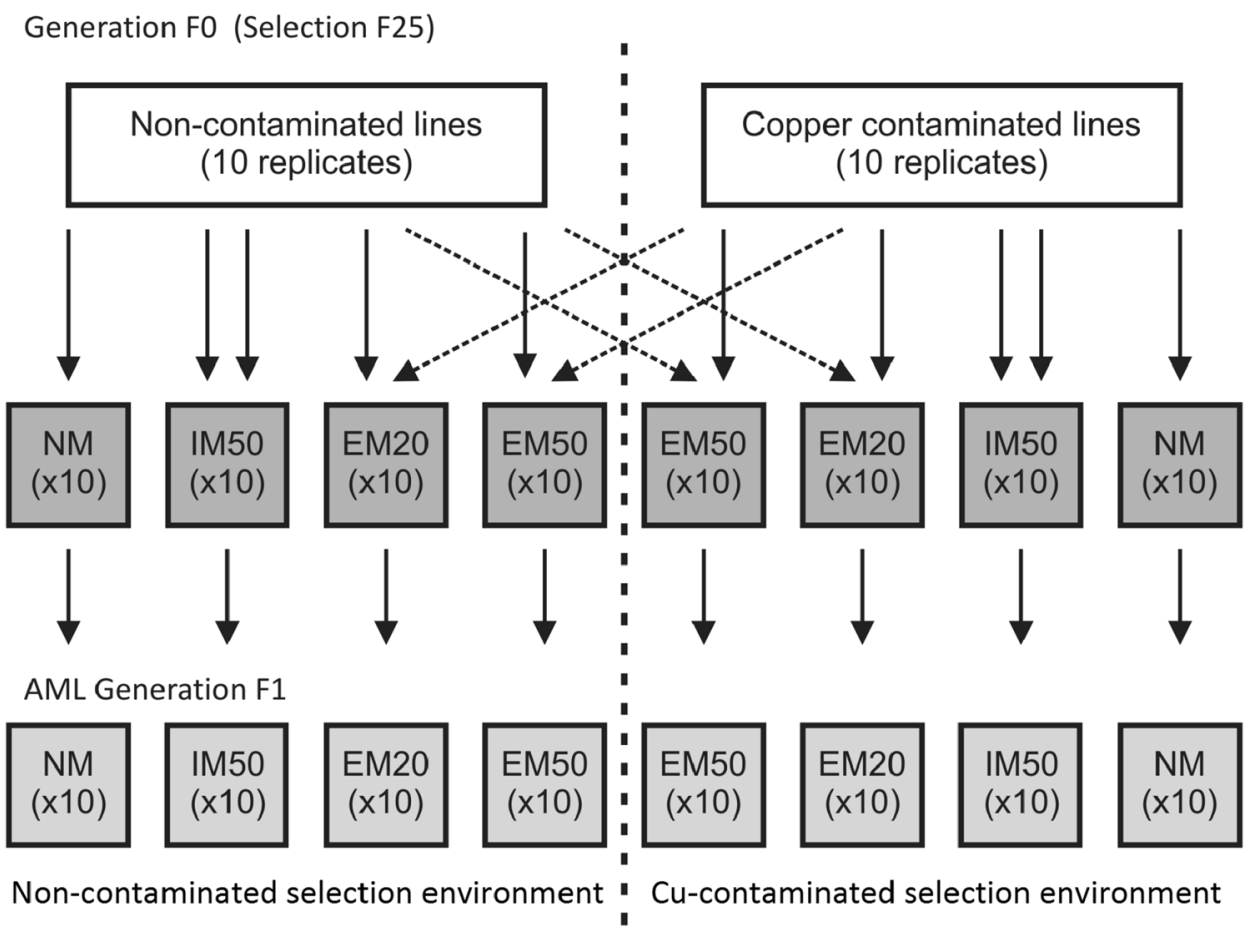

deionized water ( $300 \mathrm{~mL} \mathrm{~kg}^{-1}$ of flour). The flour mixture was dried at $105^{\circ} \mathrm{C}$ for $24 \mathrm{~h}$ and powdered using a laboratory mill (MUKF 10 type, Młynpol, Poland). The control medium was prepared using an identical procedure, but deionized water was used in place of the $\mathrm{CuCl}_{2}$ solution. To ascertain the concentrations of $\mathrm{Cu}$ in the medium the samples were prepared and analyzed according to standardized method (Bednarska and Stępień 2015). Five samples of the reference material (Ulva lactuca No 483 by CBR), analyzed together with the medium, gave a mean recovery $( \pm \mathrm{SD})$ of $92.78 \% \pm 1.02 \%$. The $\mathrm{Cu}$ concentrations $\left(\mathrm{mg} \mathrm{kg}^{-1}\right)$ that we measured in the medium matched expected values (mean $\pm \mathrm{SD}$ ): control, $4.95 \pm 0.11$; nominal $2000 \mathrm{mg} \mathrm{kg}^{-1}, 2055.19 \pm 4.89$.

The core assumptions of used model were that the uptake rate was proportional to the environmental concentration, and the elimination rate was proportional to the internal concentration, as described by Atkins (1969):

$\frac{d C_{i}}{d t}=k_{a} C_{e}-k_{e} C_{i}$

where $\mathrm{C}_{\mathrm{e}}$ is the external environmental $\mathrm{Cu}$ concentration $\left(\mathrm{mg} \mathrm{kg}^{-1}\right), \mathrm{C}_{\mathrm{i}}$ the internal body $\mathrm{Cu}$ concentration $\left(\mathrm{mg} \mathrm{kg}^{-1}\right), \mathrm{k}_{\mathrm{a}}$ is the assimilation rate constant $\left(\mathrm{day}^{-1}\right)$, and $\mathrm{k}_{\mathrm{e}}$ is the elimination rates constant $\left(\mathrm{day}^{-1}\right)$. Solving Eq. 1, the internal $\mathrm{Cu}$ concentration at time $\mathrm{t}$ is expressed as follows:

$C_{i}(t)=C_{i, t_{c}} \cdot e^{-k_{e} \cdot\left(t-t_{c}\right)}+C_{e} \frac{k_{a}}{k_{e}}\left(1-e^{-k_{e}\left(t-t_{c}\right)}\right)$ where $\mathrm{C}_{\mathrm{i}}$ represents the internal $\mathrm{Cu}$ concentration at the start of each stage $\left(\mathrm{mg} \mathrm{kg}^{-1}\right)$, and $\mathrm{t}_{c}$ is the time at which one stage transitions to the next (day). In the first stage $t_{c}=0$ and $\mathrm{C}_{i}, t_{c}=\mathrm{C}_{0}$ (i.e., the initial body $\mathrm{Cu}$ concentration at $\mathrm{t}_{0}$, $\mathrm{mg} \mathrm{kg}^{-1}$ ). Outliers for each time point were detected with Q95\% Dixon's Test and excluded from further analyses. After removing the outliers, the geometric mean recommended for TK modeling (Laskowski et al. 2010) was calculated for each time point and all models were fit to these calculated means $\left(\mathrm{C}_{\mathrm{i}}, \mathrm{t}_{\mathrm{c}}\right)$. The elimination and assimilation constants and their $95 \%$ confidence intervals (CI) were estimated using a program code developed in MATLAB (Version 8.0.0.783, R2012b). We compared the experimental groups (treatments) using the estimated confidence intervals. The chosen method is conservative and detects differences between treatments with high robustness.

\section{Results and Discussion}

Insects responded with distinct metal uptake upon external metal exposure during the intoxication phase, and in all eight treatments (Fig. 2); they eliminated metals significantly during the elimination phase. The data for all time points, after removal of outliers, were normally distributed. The last time point (day 40) was not used for estimation of model parameters because the $\mathrm{Cu}$ concentrations on that day showed extreme deviation from the observed pattern, suggesting an analytical error. 
Fig. 2 Copper kinetics in $T$. castaneum described by a twophase, four-stage model in the experiment simulating migration between $\mathrm{Cu}$-adapted and non-adapted populations
Non-contaminated environment

Copper contaminated environment
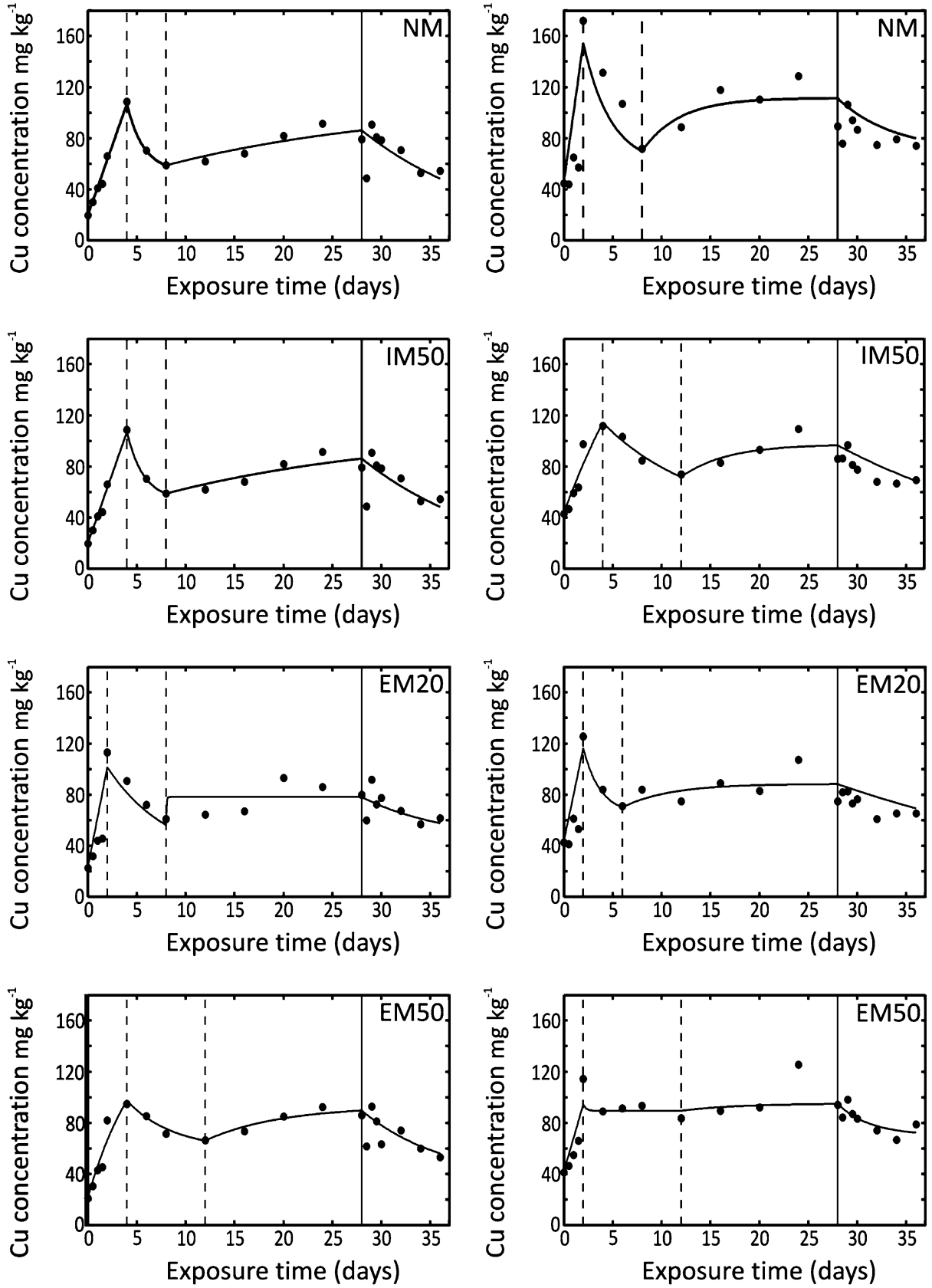

Visual data analysis revealed that the classic two-phase model (Atkins 1969) does not adequately describe the observed pattern. Following the observed pattern in data (Fig. 2), we proposed a new TK approach. We divided the intoxication phase into three distinct stages reflecting changes in organism physiology, with $\mathrm{k}_{\mathrm{a}}$ and $\mathrm{k}_{\mathrm{e}}$ rates estimated individually for each stage and numbered accordingly from 1 to 3 with subjectively demarcated breakpoints. For the first stage, we used the initial $\mathrm{Cu}$ concentration measured in the beetles at $t_{0}\left(C_{0}\right)$. The initial concentrations for the subsequent stages were calculated from the model at the time of transition between two consecutive stages (Fig. 2; Tables 1, 2). Stage 1 (accumulation stage) was characterized by a rapid increase in $\mathrm{Cu}$ concentration from time 0 to the time during the experiment at which the organisms exhibited the highest body $\mathrm{Cu}$ concentrations. In stage 2 (depuration stage) the organisms exhibited a decrease in $\mathrm{Cu}$ level. The decrease extended from the maximum concentration reached at the end of stage 1 to the lowest $\mathrm{Cu}$ concentration in the intoxication phase. Stage 3 (stabilization stage) lasted from the end of stage 2 to the end of the intoxication phase. The elimination phase made up the 
Table 1 Kinetics parameters [accumulation rate constant $\left(\mathrm{k}_{\mathrm{a}}\right)$, elimination rate constant $\left(\mathrm{k}_{\mathrm{e}}\right)$ ] related to Cu total concentrations in T. castaneum from the migration experiment (selection environment: non-contaminated medium)

\begin{tabular}{|c|c|c|c|c|c|c|}
\hline Phase & Stage & & $\mathrm{NM}$ & IM50 & EM20 & EM50 \\
\hline \multirow[t]{9}{*}{ I Intoxication } & \multirow[t]{3}{*}{1 Accumulation } & $\mathrm{k}_{\mathrm{a} 1}\left(\mathrm{day}^{-1}\right)$ & $\begin{array}{l}1.439 \times 10^{-5} \mathrm{~A} \\
\left(2.122 \times 10^{-6}-2.667 \times 10^{-5}\right)\end{array}$ & $\begin{array}{l}13.14 \times 10^{-5} \mathrm{~A} \\
(0-0.199)\end{array}$ & $\begin{array}{l}1.612 \times 10^{-5} \mathrm{~A} \\
\left(0-1.126 \times 10^{-4}\right)\end{array}$ & $\begin{array}{l}1.562 \times 10^{-5} \mathrm{~A} \\
\left(0-3.23 \times 10^{-5}\right)\end{array}$ \\
\hline & & $\mathrm{k}_{\mathrm{e} 1}\left(\mathrm{day}^{-1}\right)$ & $\begin{array}{l}1.146 \times 10^{-5} \mathrm{~A} \\
(0-0.355)\end{array}$ & $\begin{array}{l}1.093 \times 10^{-5} \mathrm{~A} \\
\left(5.331 \times 10^{-6}-1.654 \times 10^{-5}\right)\end{array}$ & $\begin{array}{l}0.467 \times 10^{-5} \mathrm{~A} \\
(0-3.872)\end{array}$ & $\begin{array}{l}0.191 \mathrm{~A} \\
(0-0.755)\end{array}$ \\
\hline & & $\mathrm{R}^{2}{ }_{1}$ & $93.8 \%$ & $98.6 \%$ & $70.9 \%$ & $91 \%$ \\
\hline & \multirow[t]{3}{*}{2 Depuration } & $\mathrm{k}_{\mathrm{a} 2}\left(\mathrm{day}^{-1}\right)$ & $\begin{array}{l}5.792 \times 10^{-6} \mathrm{~B} \\
\left(5.785 \times 10^{-6}-5.999 \times 10^{-6}\right)\end{array}$ & $\begin{array}{l}15.78 \times 10^{-6} \mathrm{~A} \\
\left(15.78 \times 10^{-6}-15.79 \times 10^{-6}\right)\end{array}$ & $\begin{array}{l}2.239 \times 10^{-6} \mathrm{~B} \\
\left(0-6.844 \times 10^{-6}\right)\end{array}$ & $\begin{array}{l}6.308 \times 10^{-6} \mathrm{AB} \\
\left(0-2.397 \times 10^{-5}\right)\end{array}$ \\
\hline & & $\mathrm{k}_{\mathrm{e} 2}\left(\mathrm{day}^{-1}\right)$ & $\begin{array}{l}0.297 \mathrm{~B} \\
(0.297-0.297)\end{array}$ & $\begin{array}{l}0.589 \mathrm{~A} \\
(0.589-0.589)\end{array}$ & $\begin{array}{l}0.160 \mathrm{C} \\
(0.051-0.269)\end{array}$ & $\begin{array}{l}0.214 \mathrm{ABC} \\
(0-0.672)\end{array}$ \\
\hline & & $\mathrm{R}_{2}^{2}$ & $100 \%$ & $100 \%$ & $99.9 \%$ & $96.6 \%$ \\
\hline & \multirow[t]{3}{*}{3 Stabilization } & $\mathrm{k}_{\mathrm{a} 3}\left(\mathrm{day}^{-1}\right)$ & $\begin{array}{l}1.343 \times 10^{-5} \mathrm{~A} \\
(0-5.346)\end{array}$ & $\begin{array}{l}2.189 \times 10^{-6} \mathrm{~A} \\
\left(0-1.099 \times 10^{-5}\right)\end{array}$ & $\begin{array}{l}8.425 \times 10^{-4} \mathrm{~A} \\
\left(0-6.147 \times 10^{-4}\right)\end{array}$ & $\begin{array}{l}6.042 \times 10^{-6} \mathrm{~A} \\
\left(0-1.946 \times 10^{-5}\right)\end{array}$ \\
\hline & & $\mathrm{k}_{\mathrm{e} 3}\left(\right.$ day $\left.^{-1}\right)$ & $\begin{array}{l}0.309 \mathrm{~A} \\
(0-1.256)\end{array}$ & $\begin{array}{l}4.094 \times 10^{-2} \mathrm{~A} \\
(0-0.282)\end{array}$ & $\begin{array}{l}21.61 \mathrm{~A} \\
\left(0-1576 \times 10^{6}\right)\end{array}$ & $\begin{array}{l}0.13 \mathrm{~A} \\
(0-0.459)\end{array}$ \\
\hline & & $\mathrm{R}_{3}^{2}$ & $28.6 \%$ & $76.7 \%$ & $31.7 \%$ & $87.8 \%$ \\
\hline \multirow[t]{3}{*}{ II Elimination } & \multirow[t]{3}{*}{4 Elimination } & $\mathrm{k}_{\mathrm{a} 4}\left(\mathrm{day}^{-1}\right)$ & $\begin{array}{l}8.157 \times 10^{-4} \mathrm{~A} \\
\left(0-5.54 \times 10^{-3}\right)\end{array}$ & $\begin{array}{l}3.102 \times 10^{-7} \mathrm{~A} \\
\left(0-9.139 \times 10^{-7}\right)\end{array}$ & $\begin{array}{l}9.908 \times 10^{-4} \mathrm{~A} \\
\left(0-7.103 \times 10^{-3}\right)\end{array}$ & $\begin{array}{l}8.116 \times 10^{-4} \mathrm{~A} \\
\left(0-1.108 \times 10^{-2}\right)\end{array}$ \\
\hline & & $\mathrm{k}_{\mathrm{e} 4}\left(\mathrm{day}^{-1}\right)$ & $\begin{array}{l}0.122 \\
(0-0.457)\end{array}$ & $\begin{array}{l}0.072 \\
(0.02-0.125)\end{array}$ & $\begin{array}{l}0.113 \\
(0-0.556)\end{array}$ & $\begin{array}{l}0.118 \\
(0-0.85)\end{array}$ \\
\hline & & $\mathrm{R}^{2}{ }_{5}$ & $94.1 \%$ & $82.4 \%$ & $84.2 \%$ & $40.8 \%$ \\
\hline
\end{tabular}

The $95 \%$ confidence intervals are shown in brackets

Coefficients of determination $\left(\mathrm{R}^{2}\right)$ describe the proportion of variance in beetle $\mathrm{Cu}$ body concentrations explained by the fitted model

Subscripted numbers associated with $\mathrm{k}$ and $\mathrm{R}$ denote the four stages of the model as follows: 1 the accumulation stage, 2 the depuration stage, 3 the stabilization stage, 4 the elimination stage

Abbreviations denote after migration lines (AML): $N M$ control lines with no migrants maintained under the same regime as in the main selection experiment, IM50 lines with 50\% 'internal' migrants (from the same environment type), EM20 and EM50 migrants derived from a line from different selection environment; $20 \%$ or $50 \%$ of migrants respectively

Differences between the confidence intervals of kinetics parameters $\left(\mathrm{k}_{\mathrm{a}}\right.$ and $\left.\mathrm{k}_{\mathrm{e}}\right)$ are shown as letters $(\mathrm{A}, \mathrm{B}, \mathrm{C})$ for a single phase, and single constant $(\mathrm{A}, \mathrm{B}, \mathrm{C})$

fourth toxicokinetic stage (elimination stage) and was characterized by a gradual decrease in $\mathrm{Cu}$ concentration.

The rapid increase in body $\mathrm{Cu}$ concentration in the first stage of the experiment (Fig. 2) was consistent with reports made by other authors for various metals and invertebrates, such as earthworms (Atkins 1969), insects (Bednarska et al. 2011; Laskowski et al. 2010; Postma et al. 1996), and crustaceans (Soedarini et al. 2012). The physiological basis of this phenomenon in T. castaneum may be the immobilization of metals in gut wall in an insoluble form-granules (Hopkin 1989; Postma et al. 1996; Rost-Roszkowska et al. 2010). This process appears to be the first defense mechanism against metal intoxication (Laskowski et al. 2010; Posthuma and Van Straalen 1993; Postma et al. 1996). The second stage showed an abrupt reduction in $\mathrm{Cu}$ concentration to the lowest values recorded in the intoxication phase. Similar reductions have been previously found and discussed by other authors (Bednarska et al. 2011; Laskowski et al. 2010; Soedarini et al. 2012). The pattern appears to result from a threshold $\mathrm{Cu}$ concentration being reached in the gut epithelium, leading to gut damage (Argasiński et al. 2012) or acclimation, and then to rapid depuration. Herein proposed hypothesis predicts massive metal accumulation in the intestine during the first stage, and an abrupt reduction during the second stage caused by gut cell exfoliation due to the toxic effect of $\mathrm{Cu}$ on epithelial cells. This phenomenon has been mechanistically described by a TK cell demography model (TKCD) (Argasiński et al. 2012), and has been described by Postma et al. (1996) for the midge Chironomus riparius. In all treatments, our data showed a clear increase in concentration after the second-stage reduction, suggesting that third stage existed in terms of animal physiology (i.e., separate $k_{a}$ and $k_{e}$ values). The slight, yet clear, increase in $\mathrm{Cu}$ concentration, and possible stabilization at a level intermediate to the maximum and minimum values, suggests some sort of acclimation. $\mathrm{Cu}$ concentration may be controlled efficiently in the contaminated environment by fine-tuning the assimilation and elimination rates. 
Table 2 Kinetics parameters [accumulation rate constant $\left(\mathrm{k}_{\mathrm{a}}\right)$, elimination rate constant $\left(\mathrm{k}_{\mathrm{e}}\right)$ ] related to total Cu concentrations in T. castaneum from the migration experiment (selection environment: $\mathrm{Cu}$-contaminated medium)

\begin{tabular}{|c|c|c|c|c|c|c|}
\hline Phase & Stage & & $\mathrm{NM}$ & IM50 & EM20 & EM50 \\
\hline \multirow[t]{9}{*}{ I Intoxication } & \multirow[t]{3}{*}{1 Accumulation } & $\mathrm{k}_{\mathrm{a} 1}\left(\mathrm{day}^{-1}\right)$ & $\begin{array}{l}2.752 \times 10^{-5} \mathrm{~A} \\
\left(0-9.75 \times 10^{-4}\right)\end{array}$ & $\begin{array}{l}1.261 \times 10^{-5} \mathrm{~A} \\
\left(0-3.452 \times 10^{-5}\right)\end{array}$ & $\begin{array}{l}1.846 \times 10^{-5} \mathrm{~A} \\
\left(0-6.180 \times 10^{-5}\right)\end{array}$ & $\begin{array}{l}1.325 \times 10^{-5} \mathrm{~A} \\
\left(0-1.281 \times 10^{-4}\right)\end{array}$ \\
\hline & & $\mathrm{k}_{\mathrm{e} 1}\left(\mathrm{day}^{-1}\right)$ & $\begin{array}{l}4.814 \times 10^{-6} \mathrm{~A} \\
\left(0-1.986 \times 10^{-5}\right)\end{array}$ & $\begin{array}{l}9.142 \times 10^{-2} \mathrm{~A} \\
(0-0.673)\end{array}$ & $\begin{array}{l}1.208 \times 10^{-5} \mathrm{~A} \\
(0-15.47)\end{array}$ & $\begin{array}{l}5.547 \times 10^{-6} \mathrm{~A} \\
(0-3.611)\end{array}$ \\
\hline & & $\mathrm{R}^{2}{ }_{1}$ & $84.1 \%$ & $89.9 \%$ & $77 \%$ & $79.6 \%$ \\
\hline & \multirow[t]{3}{*}{2 Depuration } & $\mathrm{k}_{\mathrm{a} 2}\left(\mathrm{day}^{-1}\right)$ & $\begin{array}{l}2.024 \times 10^{-7} \mathrm{~A} \\
\left(0-1.089 \times 10^{-5}\right)\end{array}$ & $\begin{array}{l}2.024 \times 10^{-6} \mathrm{AB} \\
\left(0-2.190 \times 10^{-5}\right)\end{array}$ & $\begin{array}{l}1.874 \times 10^{-5} \mathrm{~B} \\
\left(1.874 \times 10^{-5}\right. \\
\left.\quad-1.874 \times 10^{-5}\right)\end{array}$ & $\begin{array}{l}1.483 \times 10^{-4} \mathrm{AB} \\
\left(0-1.061^{-2}\right)\end{array}$ \\
\hline & & $\mathrm{k}_{\mathrm{e} 2}\left(\mathrm{day}^{-1}\right)$ & $\begin{array}{l}0.055 \mathrm{~A} \\
(0-0.306)\end{array}$ & $\begin{array}{l}0.104 \mathrm{~A} \\
(0-0.534)\end{array}$ & $\begin{array}{l}0.578 \mathrm{~A} \\
(0.578-0.578)\end{array}$ & $\begin{array}{l}3.321 \mathrm{~A} \\
(0-237.4)\end{array}$ \\
\hline & & $\mathrm{R}_{2}^{2}\left(\right.$ day $\left.^{-1}\right)$ & $99.2 \%$ & $96.3 \%$ & $100 \%$ & $90.6 \%$ \\
\hline & \multirow[t]{3}{*}{3 Stabilization } & $\mathrm{k}_{\mathrm{a} 3}\left(\mathrm{day}^{-1}\right)$ & $\begin{array}{l}1.468 \times 10^{-5} \mathrm{~A} \\
\left(0-6.127 \times 10^{-5}\right)\end{array}$ & $\begin{array}{l}1.041 \times 10^{-5} \mathrm{~A} \\
\left(0-5.927 \times 10^{-5}\right)\end{array}$ & $\begin{array}{l}9.098 \times 10^{-6} \mathrm{~A} \\
\left(0-5.160 \times 10^{-5}\right)\end{array}$ & $\begin{array}{l}8.577 \times 10^{-6} \mathrm{~A} \\
\left(7.728 \times 10^{-6}-9.385 \times 10^{-6}\right)\end{array}$ \\
\hline & & $\mathrm{k}_{\mathrm{e} 3}\left(\right.$ day $\left.^{-1}\right)$ & $\begin{array}{l}0.263 \mathrm{~A} \\
(0-1.15)\end{array}$ & $\begin{array}{l}0.214 \mathrm{~A} \\
(0-1.288)\end{array}$ & $\begin{array}{l}0.206 \mathrm{~A} \\
(0-1.208)\end{array}$ & $\begin{array}{l}0.181 \mathrm{~A} \\
(0.162-0.199)\end{array}$ \\
\hline & & $\mathrm{R}_{3}^{2}$ & $55.7 \%$ & $55 \%$ & $21.7 \%$ & $99.9 \%$ \\
\hline \multirow[t]{3}{*}{ II Elimination } & \multirow[t]{3}{*}{4 Elimination } & $\mathrm{k}_{\mathrm{a} 4}\left(\mathrm{day}^{-1}\right)$ & $\begin{array}{l}2.467 \times 10^{-3} \mathrm{~A} \\
\left(0-1.527 \times 10^{-2}\right)\end{array}$ & $\begin{array}{l}5.038 \times 10^{-8} \mathrm{~A} \\
(0-2.732 \times 10-7)\end{array}$ & $\begin{array}{l}5.298 \times 10^{-8} \mathrm{~A} \\
\left(0-1.775 \times 10^{-7}\right)\end{array}$ & $\begin{array}{l}4.175 \times 10^{-3} \mathrm{~A} \\
(0-0.015)\end{array}$ \\
\hline & & $\mathrm{k}_{\mathrm{e} 4}\left(\mathrm{day}^{-1}\right)$ & $\begin{array}{l}0.177 \mathrm{~A} \\
(0-0.970)\end{array}$ & $\begin{array}{l}0.043 \mathrm{~A} \\
(0-0.077)\end{array}$ & $\begin{array}{l}0.030 \mathrm{~A} \\
(0.005-0.055)\end{array}$ & $\begin{array}{l}0.298 \mathrm{~A} \\
(0-0.960)\end{array}$ \\
\hline & & $\mathrm{R}^{2}{ }_{5}$ & $79.6 \%$ & $67.6 \%$ & $52.9 \%$ & $94.1 \%$ \\
\hline
\end{tabular}

The $95 \%$ confidence intervals are shown in brackets

Coefficients of determination $\left(\mathrm{R}^{2}\right)$ describe the proportion of variance in beetle $\mathrm{Cu}$ body concentrations explained by the fitted model

Subscripted numbers associated with $\mathrm{k}$ and $\mathrm{R}$ denote the four stages of the model as follows: 1 the accumulation stage, 2 the depuration stage, 3 the stabilization stage, 4 the elimination stage

Abbreviations denote after migration lines (AML): $N M$ control lines with no migrants maintained under the same regime as in the main selection experiment, IM50 lines with 50\% 'internal' migrants (from the same environment type), EM20 and EM50 migrants derived from a line from different selection environment; $20 \%$ or $50 \%$ of migrants respectively

Differences between the confidence intervals of kinetics parameters $\left(\mathrm{k}_{\mathrm{a}}\right.$ and $\left.\mathrm{k}_{\mathrm{e}}\right)$ are shown as letters $(\mathrm{A}, \mathrm{B}, \mathrm{C})$ for a single phase, and single constant $(\mathrm{A}, \mathrm{B}, \mathrm{C})$

Copper is an essential element and it is generally well regulated by invertebrates. Alternatively, observed fluctuations in body $\mathrm{Cu}$ concentration may be a simple side effect of the cycles of gut epithelial cell replacement. This latter explanation is also supported by the mechanistic TKCD model (Argasiński et al. 2012), and by a model proposed by Postma et al. (1996). Laskowski et al. (2010) and Skip et al. (2014) did not distinguish this stage in their three-stage model. The fourth stage in our approach was equivalent to the elimination phase and followed the pattern commonly described in the literature (Bednarska et al. 2011; Janssen et al. 1991; Laskowski et al. 2010). After being placed on the uncontaminated medium, the beetles continuously eliminated excessive $\mathrm{Cu}$.

The one-compartment, two-phase, four-stage approach proposed in this paper fitted our data very well. The three stages of the intoxication phase, described by separate equations within dependently estimated $\mathrm{k}_{\mathrm{a}}$ and $\mathrm{k}_{\mathrm{e}}$ values, appear to reflect observed $\mathrm{Cu}$ level fluctuations and changes in animals' physiology that may occur during metal exposure. It is consistent with the description of gut physiology in metal-intoxicated invertebrates provided by Argasiński et al. (2012). The proposed approach can be considered a more detailed version of the three-stage model proposed by Laskowski et al. (2010) and Skip et al. (2014). The demonstrated approach is simplified, with subjectively demarcated breakpoints and four separately fitted equations for the four stages, because of limitations of the conducted experiment. The experiment was originally designed to compare regular two-stage kinetics in different populations of T. castaneum. Only after completing the study did it appear that the traditional two-stage model does not fit the data. Hence, the data collected were too scarce to estimate and test more complex models and did not allow for estimating the breakpoints. Nevertheless, the results suggest that the proposed approach can be used also with estimated breakpoints or 
even extended to a two-compartment model, provided the sampling is more frequent (Skip et al. 2014). To determine whether the observed changes in metal concentration can be indeed explained by cycles of gut epithelial cell shedding and replacement, detailed studies on the invertebrates' detoxification physiology are needed.

During the intoxication phase food avoidance can be the first defense mechanism against food contamination. The reduction of consumption in intoxication phase could result in body mass loss and indirectly influence copper body burden. Although direct measure of consumption rate was not available for the present experiment. We compared dry body mass of the beetles sampled at the beginning of each TK stage of the intoxication phase and at the end of intoxication phase in day 28 (two-way ANOVA for treatment and time with outlier detection; data distribution tested for normality and variance homogeneity). The results did not indicate any effect of time on body mass during the intoxication phase $\left(p=0.053 ; \mathrm{F}_{3,288}=2.656\right)$ but significant treatment effect was found $\left(p<0.001 ; \mathrm{F}_{7,288}=4.33\right)$. Interaction was not significant $\left(p=0.965 ; \mathrm{F}_{21,288}=0.512\right)$. It can be, thus, assumed that if dry body mass of the beetles did not change during the experiment, they were not starving and consumed both the contaminated and uncontaminated food similarly. The significant treatment effect indirectly pointed on inbreeding depression: individuals derived from lines that obtained migrants (internal and external) were heavier.

Few studies have investigated differences in metal toxicokinetics between metal adapted and non-adapted populations. In a population of Cd-adapted midges (Chironomus riparius), the net accumulation of $\mathrm{Cd}$ was lower, the excretion efficiency and equilibrium level were higher (Postma et al. 1996). In the springtail Orchestella cincta, adaptation to $\mathrm{Cd}$ was manifested as a higher excretion rate caused by an alteration in gut physiology (Posthuma and Van Straalen 1993). Accordingly, we expected immigrants originating from a different line type to influence $\mathrm{k}_{\mathrm{a}}$ and $\mathrm{k}_{\mathrm{e}}$ values. Comparison of the confidence intervals for the TK parameters (Tables 1,2), along with an analysis of the graphs (Fig. 2), indicated that differences between treatments in $\mathrm{k}_{\mathrm{a}}$ and $\mathrm{k}_{\mathrm{e}}$ values were negligible. We found significant differences in $\mathrm{k}_{\mathrm{a}}$ and $\mathrm{k}_{\mathrm{e}}$ values in the second stage (depuration) in lines from non-contaminated selection environment (Table 1). Accumulation rates for IM50, AML and EM20, AML differed significantly from accumulation rate for NM, AML. Elimination rates were different for three AML: NM, IM50 and EM20 (Table 1). For lines originating from $\mathrm{Cu}$-contaminated selection environment significant difference was found only for $\mathrm{k}_{\mathrm{a}}$ in the second (depuration) stage: $\mathrm{k}_{\mathrm{a}}$ value was higher in EM20 lines than in NM lines (Table 2). It is reasonable to assume that the differences were due to changes in gut physiology (Posthuma and Van Straalen 1993; Posthuma et al. 1996): storage capability and excretion efficiency ( $\mathrm{Cu}$ intake, accumulation in granules and gut epithelium exfoliation). The highest $\mathrm{k}_{\mathrm{a}}$ value reached by IM50 lines indicates that a high rate of migration could be beneficial to $\mathrm{Cu}$ uptake rate and bonding. Indirectly, it suggests that inbreeding depression for $\mathrm{Cu}$ management in NM lines is manifested by lowered $\mathrm{Cu}$ influx and storage abilities. It is difficult to compare this value to the value estimated for the EM50 treatment because of lower goodness-of-fit $\left(\mathrm{R}^{2}=96.6 \%\right)$, and wider $\left(0.0-23.97 \times 10^{-5}\right)$ CI (confidence interval) overlapping the CI for the NM treatment (Table 1). Also the IM50 lines had the highest elimination rate significantly higher than for NM lines and for EM20 lines. Because the CI was widest for EM50 lines $\left(0.000-0.672\right.$ day $\left.^{-1} ; \mathrm{R}^{2}=96.6 \%\right)$ and overlapped with the CIs of the other treatments it is impossible to discuss effects of external immigrants. This result again indirectly suggests that inbreeding depression for $\mathrm{Cu}$ management in NM lines is manifested as less efficient $\mathrm{Cu}$ excretion.

The duration of subsequent stages during the intoxication phase should be also analyzed and discussed in terms of gut physiology and defense mechanisms combined with gut epithelium exfoliation. Nonetheless, it is difficult to find a clear pattern for differences between treatments (groups). The difference that was most pronounced was the prolongation of the second (depuration) stage in lines from noncontaminated environment reinforced with migrants coming from copper-contaminated environment from 4 days in NM AML to 6 days in EM20 AML and 8 days in EM50 AML (Fig. 2). The duration of this stage in NM AML lines from copper-contaminated environment was 6 days. It can be stated that depuration process after reaching the maximal copper body burden during the intoxication phase was longer in lines derived from contaminated environment and this trait was transferred to lines from non-contaminated environment by migrants. The physiological mechanism of the observed phenomenon can be higher resistance to copper intoxication (via gut epithelium) of the beetles derived from the contaminated environment followed by slower gut exfoliation and removal of the deposited copper.

The lack of unequivocal influence of migrants in the lines from $\mathrm{Cu}$-contaminated selection environment indirectly suggests that the lines suffered less from inbreeding and contamination than lines derived from non-contaminated environment, or that inbreeding depression for $\mathrm{Cu}$ management was so strong that migrants were not able to enhance the investigated traits (Tables 1,2 ). The former hypothesis would suggest a beneficial influence of mild $\mathrm{Cu}$ stress on inbred populations. Marr et al. (2006) showed that in a population of wild song sparrows, inbreeding depression had a lesser influence on laying date in colder years. Dahlgaard and Hoffmann (2000) showed that heat stress had no effect on inbreeding in fruit flies. Therefore, 
we cannot reject the hypothesis that intermediate levels of $\mathrm{Cu}$-contamination could mitigate inbreeding depression in T. castaneum. This hypothesis is in stark contrast to the stress hypothesis which assumes that inbreeding depression is enhanced by harsh environments. Armbruster and Reed (2005) observed this trend empirically in $75 \%$ of the cases included in their metaanalysis but they also observed counter examples. However, in certain circumstances this may not be the case.

Furthermore, it must be noted that significant differences were found for the TK stage with the highest goodness-offit and the narrowest $\mathrm{CI}\left(\mathrm{R}^{2}\right.$ values $96.6 \%-100 \%$; Table 1$)$. This finding indicates that TK experiments must be very densely sampled and the models must show high goodnessof-fits if TK models are to be a useful tool for comparing different treatments.

Acknowledgements The research was financed by a National Science Center Poland Grant (decision Number DEC-2011/01/N/ NZ8/00112) and supported by Jagiellonian University (DS 758).

\section{Compliance with Ethical Standards}

Conflict of interest We confirm herein that there is no conflict of interest among the authors, the participating institutions or between the authors and potential reviewers.

Research Involving Animal and Human Rights The research did not involve human participants or animals other than insects.

Open Access This article is distributed under the terms of the Creative Commons Attribution 4.0 International License (http:// creativecommons.org/licenses/by/4.0/), which permits unrestricted use, distribution, and reproduction in any medium, provided you give appropriate credit to the original author(s) and the source, provide a link to the Creative Commons license, and indicate if changes were made.

\section{References}

Argasiński K, Bednarska A, Laskowski R (2012) The toxicokinetics cell demography model to explain metal kinetics in terrestrial invertebrates. Ecotoxicology 21:2186-2194

Armbruster P, Reed DH (2005) Inbreeding depression in benign and stressful environments. Heredity 95:235-242

Atkins GL (1969) Multicompartment models for biological systems. Methuen, London

Bednarska AJ, Stępień K (2015) Concentration dependent toxicokinetics of copper in the red flourbeetle Tribolium castaneum (Coleoptera: Tenebrionidae). Ecotoxicology 24(9):1823-1830

Bednarska AJ, Brzeska A, Laskowski R (2011) Two-phase uptake of nickel in the ground beetle Pterostichus oblongopunctatus (Coleoptera: Carabidae): implications for invertebrate metal kinetics. Arch Environ Contam Toxicol 60:722-733
Carlson SM, Cunningham CJ, Westley PAH (2014) Evolutionary rescue in a changing world. Trends Ecol Evol 29:521-530

Dahlgaard J, Hoffmann GA (2000) Stress resistance and environmental dependency of inbreeding depression in Drosophila melanogaster. Conserv Biol 14:1187-1192

Flemming CA, Trevors JT (1989) Copper toxicity and chemistry in the environment: a review. Water Air Soil Pollut 44:143-158

Hopkin SP (1989) Ecophysiology of metals in terrestrial invertebrates. Elsevier, New York

Janssen MPM, De Vries BTH, van Straalen NM (1991) Comparison of cadmium kinetics in four soil arthropod species. Arch Environ Contam Toxicol 20:305-312

Łagisz M, Kramarz P, Niklinska M (2005) Metal kinetics and respiration rates in $\mathrm{F} 1$ generation of carabid beetles (Pterostichus oblongopunctatus $\mathrm{F}$.) originating from metal-contaminated and reference areas. Arch Environ Contam Toxicol 48:484-489

Laskowski R, Bednarska AJ, Spurgeon D, Svendsen C, van Gestel CAM (2010) Three-phase metal kinetics in terrestrial invertebrates exposed to high metal concentrations. Sci Total Environ 408:3794-3802

Lopez S, Rousset F, Shaw FH, Shaw RG, Ronce O (2009) Joint effects of inbreeding and local adaptation on the evolution of genetic load after fragmentation. Conserv Biol 23:1618-1627

Marr AB, Arcese P, Hochachka WM, Reid JM, Keller LF (2006) Interactive effects of environmental stress and inbreeding on reproductive traits in a wild bird population. J Anim Ecol 75:1406-1415

Newman MC (2009) Fundamentals of ecotoxicology. CRC Press, Boca Raton

Posthuma L, van Straalen NM (1993) Heavy-metal adaptations in terrestrial invertebrates: a review of occurrence, genetics, physiology and ecological consequences. Comp Biochem Physiol C 106:11-38

Posthuma L, Hogervorst RF, van Straalen NM (1992) Adaptation to soil pollution by cadmium excretion in natural populations of Orchesella cincta (L.) (Collembola). Arch Environ Contam Toxicol 22:146-156

Postma JF, van Nugteren P, Buckert-de Jong MB (1996) Increased cadmium excretion in metal adapted populations of the midge Chironomus riparius (Diptera). Environ Toxicol Chem 15:332-339

Reed DH (2004) Extinction risk in fragmented habitats. Anim Conserv 7:181-191

Rost-Roszkowska MM, Poprawa I, Chachulska-Zymełka A (2010) Apoptosis and autophagy in the midgut epithelium of Acheta domesticus (Insecta, Orthoptera, Gryllidae). Zool Sci 27:740-745

Skip B, Bednarska AJ, Laskowski R (2014) Toxicokinetics of metals in terrestrial invertebrates: making things straight with the onecompartment principle. PLoS ONE 9(9):e108740. doi:10.1371/ journal.pone.0108740

Soedarini B, Klaver L, Roessink I, Widianarko B, van Straalen NM, van Gestel CAM (2012) Copper kinetics and internal distribution in the marbled crayfish (Procambarus sp.). Chemosphere 87:333-338

Sokoloff A (1974) The biology of tribolium, vol 2. Clarendon Press, Oxford

Soule ME, Wilcox B (1980) Conservation biology: an evolutionaryecological perspective. Sinauer Associates, Sunderland 